\title{
Mean-reversion in income over feed cost margins: Evidence and implications for managing margin risk by US dairy producers
}

\author{
M. Bozic, ${ }^{\star 1}$ J. Newton, $\dagger$ C. S. Thraen, $\nmid$ and B. W. Gould \\ *Department of Applied Economics, University of Minnesota-Twin Cities, Saint Paul 55108 \\ †Department of Agricultural, Environmental, and Development Economics, The Ohio State University, Columbus 43210 \\ ‡Department of Agricultural and Applied Economics, University of Wisconsin, Madison 53706
}

\section{ABSTRACT}

With the increased volatility of feed prices, dairy farm managers are no longer concerned with managing only milk price volatility, but are considering the adoption of risk management programs that address income over feed cost (IOFC) margin risk. Successful margin risk management should be founded on an understanding of the behavior of IOFC margins. To that end, we have constructed forward IOFC margins using Class III milk, corn, and soybean meal futures prices. We focus on the characteristics of the term structure of forward IOFC margins, that is, the sequence of forward margins for consecutive calendar months, all observed on the same trading day. What is apparent from the shapes of these term structures is that both in times when margins were exceptionally high and in times when they were disastrously low, market participants expected that a reversal back to average margin levels would not come quickly, but rather would take up to 9 mo. Slopes of the forward margin term structure before and after most of the major swings in IOFC indicate these shocks were mostly unanticipated, whereas the time needed for recovery to normal margin levels was successfully predicted. This suggests that IOFC margins may exhibit slow mean-reverting, rather than predictable cyclical behavior, as is often suggested in the popular press. This finding can be exploited to design a successful catastrophic risk management program by initiating protection at 9 to 12 mo before futures contract maturity. As a case study, we analyzed risk management strategies for managing IOFC margins that used Livestock Gross Margin for Dairy Cattle insurance contracts and created 2 farm profiles. The first one represents dairy farms that grow most of their feed, whereas the second profile is designed to capture the risk exposure of dairy farms that purchase all their dairy herd, dry cow, and heifer feed. Our case study

\footnotetext{
Received June 7, 2012.

Accepted September 1, 2012.

${ }^{1}$ Corresponding author: mbozic@umn.edu
}

of this program encompasses the 2009 period, which was characterized by exceptionally poor IOFC margin conditions. We analyzed the dynamics of realized IOFC margins in 2009 under 4 different risk management strategies and found that optimal strategies that were founded on the principles delineated above succeeded in reducing the decline in IOFC margins in 2009 by $93 \%$ for the Home-Feed profile and by $47 \%$ for the Market-Feed profile, and they performed substantially better than alternative strategies suggested by earlier literature.

Key words: risk management, income over feed cost margin, Livestock Gross Margin for Dairy Cattle program

\section{INTRODUCTION}

On a typical dairy farm, the cost of feed can range from 50 to $70 \%$ of the total operating cost to produce a kilogram of milk. The increase in feed exports, US gasoline policies, a mandated minimum percentage of corn-based ethanol blends, and general macroeconomic instability have all contributed to both increased levels and volatility of corn and soybean prices. With these feeds being the foundation of most dairy rations, dairy farm managers are no longer concerned with managing only revenue volatility, but are also considering the adoption of risk management programs that address the income over feed cost (IOFC) margin risk.

Successful margin risk management must be founded on understanding the behavior of IOFC margins. Three issues stand out as particularly important. First, what is the magnitude of IOFC margin volatility? Second, when IOFC margin declines, how long does it take the margin to recover to an average level? And finally, are oscillations in IOFC margins predictable? Nicholson and Stephenson (2010) decomposed All-Milk prices over the 1988 to 2010 period to cycles of different lengths and claimed that predictable cycles explained much of the variability in milk prices. They found the 36 -mo cycle to have become the largest component of cyclical variation, and stated that the length is consistent with 
biological constraints on the time needed to expand a dairy herd. The dynamic model of the US dairy sector used by these authors also produces a substantial cyclical component in All-Milk price dynamics. In this article, we examine whether expectations regarding future IOFC margins, as embedded in the futures prices, are consistent with predictable multiyear oscillations around average margin levels. Answers to the stated questions inform the design of risk management strategies presented in the second part of the article.

To answer the questions regarding the magnitude and predictability of oscillations in IOFC margins, we constructed forward IOFC margins using futures prices for Class III milk $\left(f_{t, i}^{M}\right)$, corn $\left(f_{t, i}^{C}\right)$, and soybean meal $\left(f_{t, i}^{S B M}\right)$. The subscript $i$ denotes a particular month for which the forward margin will be calculated. This is the same set of prices currently used in the Livestock Gross Margin for Dairy Cattle (LGM-Dairy) program that is being promoted as a tool to protect minimum IOFC margins (Valvekar et al., 2010). Although no ambiguity exists in the level of futures prices, constructing forward IOFC margins involves no single approach, given that dairy rations and feed price risk exposure vary across farms. For a producer who grows most of the feed required for milk production, a forward IOFC margin would reflect a lower feed market price risk compared with a dairy operator who purchases most of the feed and is therefore vulnerable to adverse feed price shocks.

To facilitate our discussion, we took as a starting point the IOFC margin first suggested by the National Milk Producers Federation (2010) and adopted in modified form in the 112th Congress US House of Representatives bill H.R. 6038, referred to as the Federal Agriculture Reform and Risk Management Act of 2012 (Farm Bill; US House of Representatives, 2011). The IOFC margin, as proposed in the 2012 Farm Bill, is defined as the farm-level value of a hundredweight of milk minus the specific feed ration, composed (by wt) of $58.8 \%$ corn, $14.4 \%$ soybean meal, and $26.8 \%$ alfalfa hay, with a total ration weight of $46.34 \mathrm{~kg}$. The ration cost is calculated as the sum of 1.0728 times the U.S average price of corn $(\$ / \mathrm{bu}), 0.00735$ times the US average price of soybean meal (\$/ton), and 0.0137 times the average price of alfalfa hay (\$/ton). To be able to calculate forward IOFC margins, we had to use prices of commodities actively traded on futures markets. The Farm Bill stipulates that the US All-Milk price be used to value milk production. Although no futures contract is written on the reported US All-Milk price, we can exploit the fact that the announced Class III milk price and reported monthly All-Milk prices have been extremely highly correlated over the period from 2000 to 2012 , with a correlation coefficient of 0.966 . We pro- ceeded by using basis-adjusted Class III futures prices, where, for tractability, we added $\$ 1.40$ to each futures price, that is, the average difference between the US All-Milk and announced Class III prices observed over the 2000 to 2012 period.

In addition, unlike corn and soybean meal, alfalfa hay does not trade on organized futures markets. To obtain a measure of the expected future alfalfa hay costs, we regressed the monthly alfalfa hay price received by US farmers on the monthly prices received for corn and soybean meal. The estimation period used was January 2005 to June 2012. Regression results are given in Table 1. On the basis of regression results, a ton of alfalfa hay is converted to $25.96 \mathrm{bu}$ of corn and -0.135 tons of soybean meal. Given the proposed utilization of alfalfa hay listed above, after conversion was performed, the final corn and soybean meal equivalents per hundredweight of milk were 1.4248 bu of corn and 0.005503 tons of soybean meal per hundredweight of milk produced. The intercept from the regression of hay on corn and soybean meal prices, multiplied by the use of alfalfa hay per hundredweight of milk, subtracts $\$ 0.995$ from the basis. Given these specifications, the time- $t$ expected per hundredweight IOFC margin $E_{t}\left(\mathrm{IOFC}_{i}\right)$ for month $i$ is given by

$$
E_{t}\left(\mathrm{IOFC}_{i}\right)=\$ 0.305+f_{t, i}^{M}-1.4248 f_{t, i}^{C}-0.005503 f_{t, i}^{S B M} .
$$

Figure 1 is used to illustrate the behavior of forward margins over the 1998 to 2011 period. The thin solid line plots realized margins, that is, margins calculated using terminal futures prices for milk and feed contracts for the period 1998 through 2011. For example, corn and soybean meal futures contracts for December 2008 last traded on December 14, 2008, for $\$ 3.60 / \mathrm{bu}$ and $\$ 258.50 /$ ton. On that day, December 2008 Class III milk futures traded for $\$ 15.11 /$ cwt. Inserting these prices in equation (1) yielded an IOFC margin level of $\$ 8.86 / \mathrm{bu}$ or $\$ 195.4 / \mathrm{Mg}$. Inspection of Figure 1 reveals a well-known pattern in the IOFC margin with an apparent 3-year cycle: peaks in 2001, 2004, and 2007, and dips in 2000, 2003, 2006 along with a major trough in

Table 1. Regression of US alfalfa hay prices (\$/ton) on US corn and soybean meal prices

\begin{tabular}{lccc}
\hline Item & Coefficient & $\mathrm{SE}$ & $t$-statistic \\
\hline Variable & & & \\
Intercept & 72.639 & 5.703 & 12.736 \\
Soybean meal price $(\$ /$ ton $)$ & -0.135 & 0.031 & -4.300 \\
Corn price (\$/bu) & 25.956 & 1.669 & 15.551 \\
Observations (no.) & 90 & & \\
$\mathrm{R}^{2}$ & 0.82 & & \\
\hline
\end{tabular}




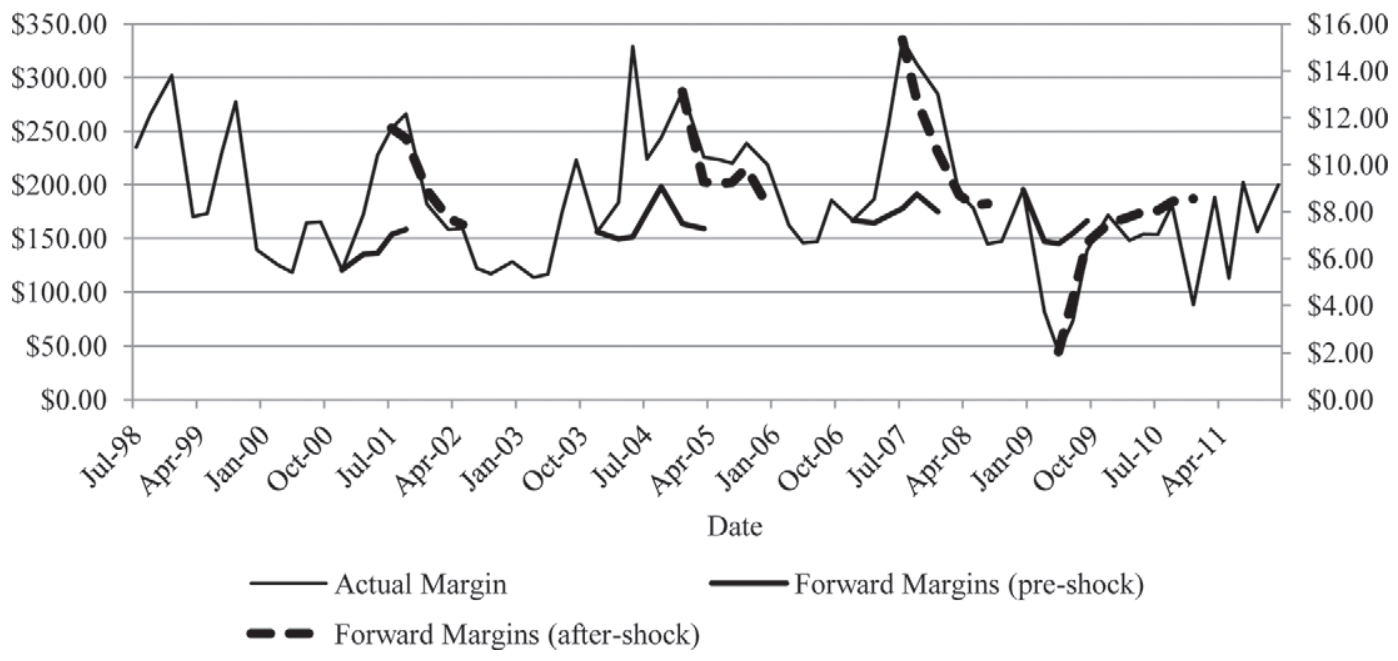

Figure 1. Unexpected shocks and expected recovery in dairy gross margins.

2009. The range of realized margins revealed immense margin volatility faced by dairy farmers. The difference between the maximum and the minimum realized IOFC margin was higher than $\$ 300 / \mathrm{Mg}(\$ 13 / \mathrm{cwt})$, and the coefficient of variation was 0.33 .

For this analysis, we focus not on realized IOFC margins, but on the characteristics of the term structure of forward IOFC margins. The term structure of futures prices is defined as the set of futures prices for different delivery months, observed at a single point in time. Likewise, the term structure of forward IOFC margins is the sequence of forward margins for consecutive calendar months, all observed on the same trading day. In Figure 1, the thick black solid and dashed lines illustrate 8 different observations of the forward margin term structure. The dashed line represents the forward margin term structure after 4 major shocks to the IOFC margin: July 2001, December 2004, July 2007, and May 2009. Each term structure is calculated based on futures prices for milk and feeds for up to at least 12 calendar months, at the middle of the months indicated above. For example, the December 2003 forward margin term structure is calculated using daily settle futures prices on December 15, 2003. Futures prices for March, May, July, September, and December 2004, as well as March 2005 were collected, and margins for the respective months were calculated using equation (1). The short dashed line starting in December 2003 connects the calculated forward margins. What is apparent from the shapes of these term structures is that in times when margins were exceptionally high and when they were disastrously low, market participants expected that a reversal back to average margin levels would not come quickly, but rather would take up to 9 mo. It should be noted that although futures market prices are a good predictor of the time needed to return to average margins, they are, in fact, no better in timing the start of margin recovery than they are in predicting the occurrence of a major shock. For example, in January 2009, the futures market pointed to milk price recovery beginning in March 2009, whereas the extremely low milk prices persisted until July 2009.

Forward margins can also be used to gain insight into the existence, regularity, and predictability of apparent multiyear cycles. If such cycles were indeed a stable characteristic of IOFC margins, then it would follow that high volatility in IOFC margins is not to be equated with high risk to dairy producers. That is, as long as average long-run margins provide adequate returns, the stability of multiyear cycles means that oscillations around the average would be mostly predictable. If futures markets are efficient, that is, if futures prices fully account for predictable future supply and demand shifts, then the term structure of forward IOFC margins would reflect predictable cyclical declines in margin, making it impossible to use futures and options to protect against such parts of the cycle. The only effective cash flow smoothing approach would then be to use windfall profits from above-average margin periods to compensate for inevitable and predictable low-margin parts of the cycle.

Do forward IOFC margins indicate that deviations from the average margin level in the past decade were predictable? The thick solid line in Figure 1 represents the forward margin term structure immediately preceding major shocks to dairy gross margins: December 
2000, December 2003, December 2006, and December 2008. How well did the market anticipate the margin shocks that followed? From Figure 1, it is apparent that the answer is not well at all. Rather than being sloped to indicate predictable cycles, the term structure curves of forward margins are mostly flat, accounting only for intrayear seasonality. If 3-year cycles did exist, the futures markets did not seem to reflect this. Even if some commodity traders were betting on such an outcome, that was clearly not the market consensus.

The above analysis for margin risk management has 3 principal implications. First, farmers may not want to time major operation expansions based on expectations of above-average milk prices that a predictable 3 -year cycle would entail, because oscillations of IOFC margins may not have much predictability after all.

Second, and more important for risk management purposes, it is the futures-based forward margins that matter because these are the prices one can use to protect future cash flows. It may appear counterintuitive at first, but the lack of ability of futures markets to anticipate major margin declines is, in fact, beneficial for risk management purposes. If futures markets had been correctly anticipating the collapse of dairy margins in 2009, they would have been completely useless for hedging against that catastrophic event.

Finally, if the expected duration of price recovery when margins are exceptionally low can take up to 9 mo, then trying to insure nearby cash flow is similar to purchasing home insurance while smoke is already coming from the attic. The available margins one can lock in after a major adverse shock has already occurred will likely be inadequate to preserve short-term profitability. The flip side of this argument comes from realizing that the forward margins available before major shocks are generally at the level matching long-run averages. This suggests that a smart risk management program would include protecting deferred rather than nearby margins.

Figure 2 is used to show an evolution of forward margins from 17 mo to maturity through the expiration of each contract. Each line on the figure depicts the evolution of a particular forward IOFC margin for a single contract month. All contract months between September 1998 and December 2011 are included in the figure. The wide dispersion at the right end of the figure [i.e., margins varying from $\$ 45$ to $\$ 335 / \mathrm{Mg}$ of milk ( $\$ 2.02$ to $\$ 15.20 /$ cwt)] is merely a different way to illustrate the volatility in realized margins. More important, from 1998 to 2011, not a single month passed in which a producer was unable to establish at least $\$ 154 / \mathrm{Mg}(\$ 7.00 /$ cwt) IOFC at some point between 9 and 12 mo before contract maturity. Uninsurable catastrophic risks indeed exist in animal agriculture. However, they reside primarily in production, not the marketing side of the business. For example, as late as October 2008, Class III futures prices were trading at more than $\$ 340 / \mathrm{Mg}$ $(\$ 15.50 /$ cwt) for any contract month in 2009. Although 2009 was indeed a catastrophic year for dairy producers, it may have been due more to the underutilization of available risk management tools than to being presented with a market risk that could not be hedged.

\section{MATERIALS AND METHODS}

\section{Analysis of Alternative Risk Management Strategies}

Early analyses of dairy revenue risk management using dairy futures contracts include those by Fortenbery et al. (1997), Fortenbery and Zapata (1997), and Thraen (1999). These papers sought to identify whether futures contracts introduced in the 1990s provided sufficient linkage with cash milk prices to justify hedging at all. A second generation of papers focused on managing the downside milk price risk. Bamba and Maynard (2004) focused on measures of tail risk (i.e., large adverse price changes) and found a 7-mo hedge horizon to be more effective than a hedge placed 4 mo to contract expiration. Maynard et al. (2005) found that hedging using Class III milk futures with a 4-mo hedging interval would have eliminated between 24 and $58 \%$ of the mailbox price semivariance over the 2000 to 2003 period. (The semivariance of a variable is a measure of the dispersion of all observations that fall below the mean or target value of this variable. The semivariance is an average of the squared deviations of values that are less than the mean or target value.) More recently, Valvekar et al. (2010) analyzed risk management strategies for protecting IOFC margins by using the Livestock Gross Margin for Dairy Cattle (LGM-Dairy), and Valvekar et al. (2011) found that its use could increase the expected utility for risk-averse dairy producers. Given the recent experience of catastrophically low IOFC margins in 2009, a need existed to examine how effective different risk management strategies would have been in protecting dairy farm profits in case of such massive market turmoil.

As shown by the previous studies, under market conditions characterized by stable feed prices, volatility in dairy farm profits could be addressed by focusing on the volatility of mailbox milk prices. With recent increases in the level of and volatility in feed grain prices, the focus of attention turns from trying to manage milk price volatility to one of managing dairy IOFC volatility. A variety of risk management strategies can be used to that end. Perhaps the most intuitive strategy is simply to acquire or rent enough land to grow all or most needed feedstuffs. If that option is not avail- 
\$/Mg of milk

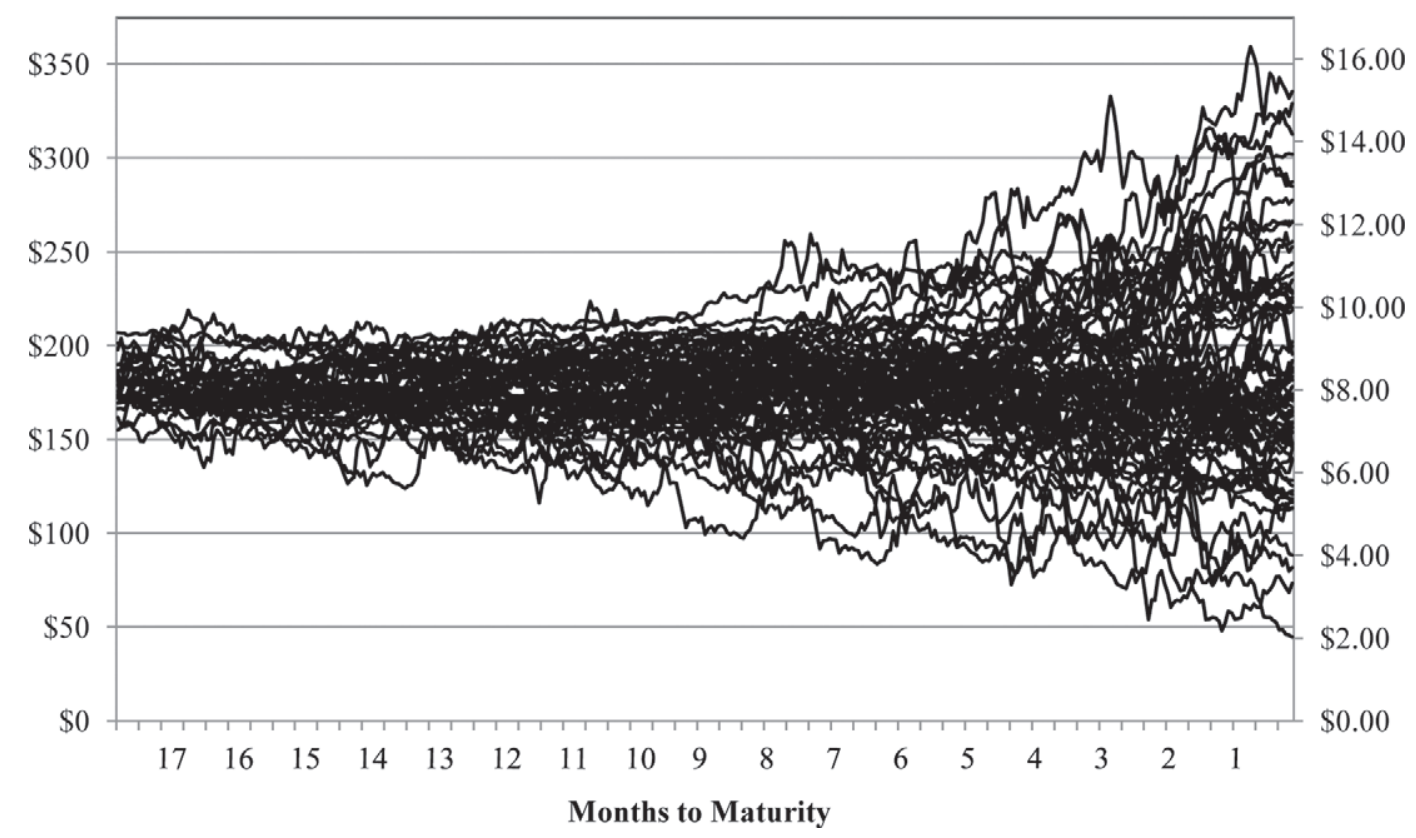

Figure 2. Forward dairy margins, 1998 to 2011.

able, or is deemed unattractive, one alternative could be to forward contract expected feed purchases and use conventional futures or options-based strategies for managing the milk price risk.

A more sophisticated, if likely more expensive, strategy as well would be to use a milk-feed options bundle (Gould and Cabrera, 2011). Under the options bundle strategy, purchasing Class III put options sufficient to cover monthly milk marketing establishes a Class III milk price (and revenue) floor. Given an estimate of the corn and soybean meal equivalents required to produce this milk, purchasing the necessary feed call options can be used to establish a ceiling on feed equivalent costs. With the establishment of a feed cost ceiling and a milk revenue floor, the IOFC margin floor has been established.

To understand the benefits and shortcomings of the milk-feed options bundle approach, a simplified illustration of the bundled-option strategy is given in Figure 3. In this figure, the solid line presents the net payoff from a put option on milk futures (i.e., including cash revenue from milk sales at the going market price), whereas the net payoff from a call option on feed futures is given by the dotted line. The flat portion of the solid line depicts the strike price for the milk put option minus the option premium and associated brokerage fees. Similarly, the horizontal portion of the dotted line is found by adding the feed option premium to the call option strike price. Should the realized milk price be higher than the put option strike price, the producer would let the milk option expire as worthless and would benefit from the upside potential this strategy preserved. Likewise, if the feed price declines, the call option on feed futures would not be exercised, and feed would instead be purchased at the lower (than call) price. In the opposite situation, in which the milk price declines, the feed price increases, or both, the IOFC floor protection is activated (i.e., the put and call options are exercised) and the producer's minimum IOFC margin will be guaranteed.

The usual complaints about the options bundle strategy include contract lumpiness, basis risk, inabil-

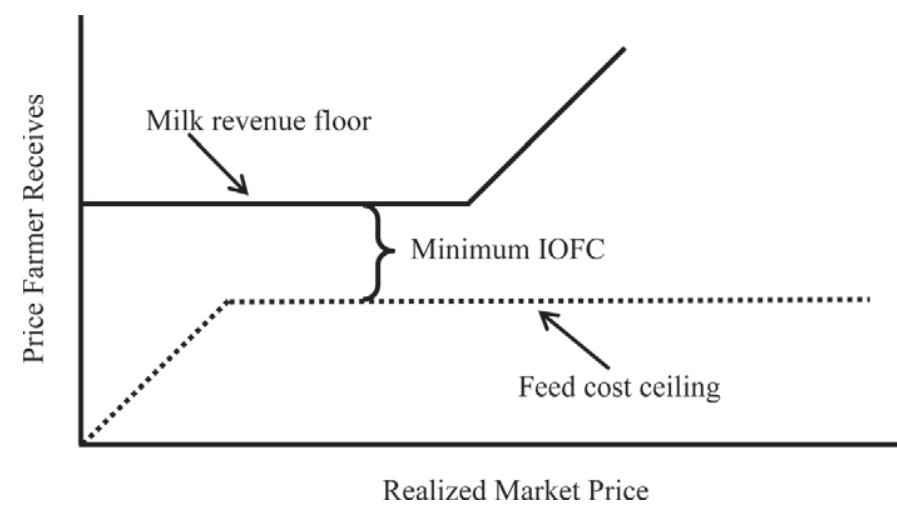

Figure 3. Use of the bundled options strategy to establish an income over feed cost (IOFC) floor. 
ity to purchase the desired Class III options given the thinness in deferred Class III options markets, and the cost of undertaking such a strategy. One fundamental shortcoming that is rarely recognized, however, is that this strategy overinsures the farm profits. In particular, using the options bundle approach protects more than just the IOFC floor. To see why, consider a situation in which both milk and feed prices increase such that the IOFC margin stays the same. Such a change in the pricing environment would have no effect on the profits of this dairy farmer, yet the options bundle strategy would produce a payoff on the feed call options side. The implication is that the options bundle approach is an imperfect method of protecting the IOFC margin floor. That is, a contract that would protect the IOFC margin floor but would not trigger payouts for proportional changes in milk and feed prices that leave the IOFC margin unchanged would be cheaper than the above-stated bundled options package.

Because IOFC margins are farm specific, no privately designed IOFC margin contract exists at the Chicago Mercantile Exchange or any other public exchange. Instead, such risk management strategies are made possible through government-sponsored LGM-Dairy insurance. The LGM-Dairy program is administered by the US Department of Agriculture's Risk Management Agency and is made available via authorized crop insurance agents to dairy farm operators in the lower 48 states. This program can be characterized as being quite flexible and size neutral. It is size neutral in the sense that no minimum contract size exists, and any amount of milk marketing up to 240,000 cwt can be insured at one time. In addition, 2 farms with the same per-cow productivity, declared feed use, and insurance contract design will pay the same premium per insured hundredweight of milk regardless of farm size. The insurance design is very flexible, given that the contract can account specifically for the market risk faced by a particular dairy operation as well as the different degrees of desired coverage. Finally, the buyer of an LGM-Dairy contract can select the level of deductible, that is, the magnitude of revenue shortfall that has to be exceeded before any indemnities are due.

Under LGM-Dairy, expected gross returns are based on Class III milk futures, corn and soybean meal futures prices at the time the insurance contract is purchased, and the amount of milk and feed desired to be insured. Class III milk futures are the most liquid dairy futures contract, with an actively trading options market, making that contract a natural choice for a basket optiontype product such as LGM-Dairy. However, because no other dairy futures and options are used, it could pose a considerable basis risk for producers with high Class
I or Class IV milk utilization (Newton and Thraen, 2012). Indemnities under LGM-Dairy are determined by the difference in expected and actual gross revenues, where the actual gross revenues are based on futures market milk and feed settle prices at futures contract expiration. For a more detailed discussion of the LGMDairy insurance program and an evaluation of its performance, refer to Valvekar et al. (2010) and Gould and Cabrera (2011).

As the above analysis emphasizes, important reasons exist to focus on margin rather than milk price risk management, and potentially significant savings can be achieved by using LGM-Dairy rather than separate financial instruments to protect cost and revenue streams. One further benefit is revealed upon realizing that the true risk to dairy producers comes not from a single month of negative cash flow, but from the possibility of prolonged periods of exceptionally low margins. Short-lived oscillations to the cash flow can easily be smoothed out by cutting variable costs, by drawing on cash reserves and operating lines of credit, or by taking loans against the farm equity. Such equity-based self-insurance is ill-suited, however, for riding through a deep crisis such as that in 2009. Some estimates indicate that as much as $30 \%$ of dairy farm equity was lost that year, and very few farms could afford a self-insurance strategy as a risk management approach for the next crisis of similar magnitude (AgWeb, 2010). In other words, a need exists for a catastrophic risk management tool that would insure average IOFC margins, rather than an IOFC margin for a single month. Just as the options bundle approach was revealed to be inferior to genuine margin-based insurance, so is insuring a single month inferior to protecting multiple months under the same contract. The probability that IOFC margins will decline is always higher than the probability that IOFC margins will decline and stay below the average level for several consecutive months. Contracts that insure average IOFC margins over a longer time will thus be relatively cheaper than a sequence of comparable insurance contracts that protect IOFC margins one month at a time. The LGM-Dairy program can easily accommodate the need for catastrophic risk insurance because up to 10 mo can be insured on a single contract.

Valvekar et al. (2010) proposed a cost-minimizing tool for the analysis of how LGM-Dairy can be used to obtain a prespecified target net IOFC margin for all milk produced on the farm, regardless of whether that milk was actually insured. Valvekar et al. (2011) used this tool to examine the welfare effects of risk management. Figure 4 shows the characteristic pattern of monthly coverage in such cost-minimizing LGM-Dairy contracts found in these analyses. The pattern is one 


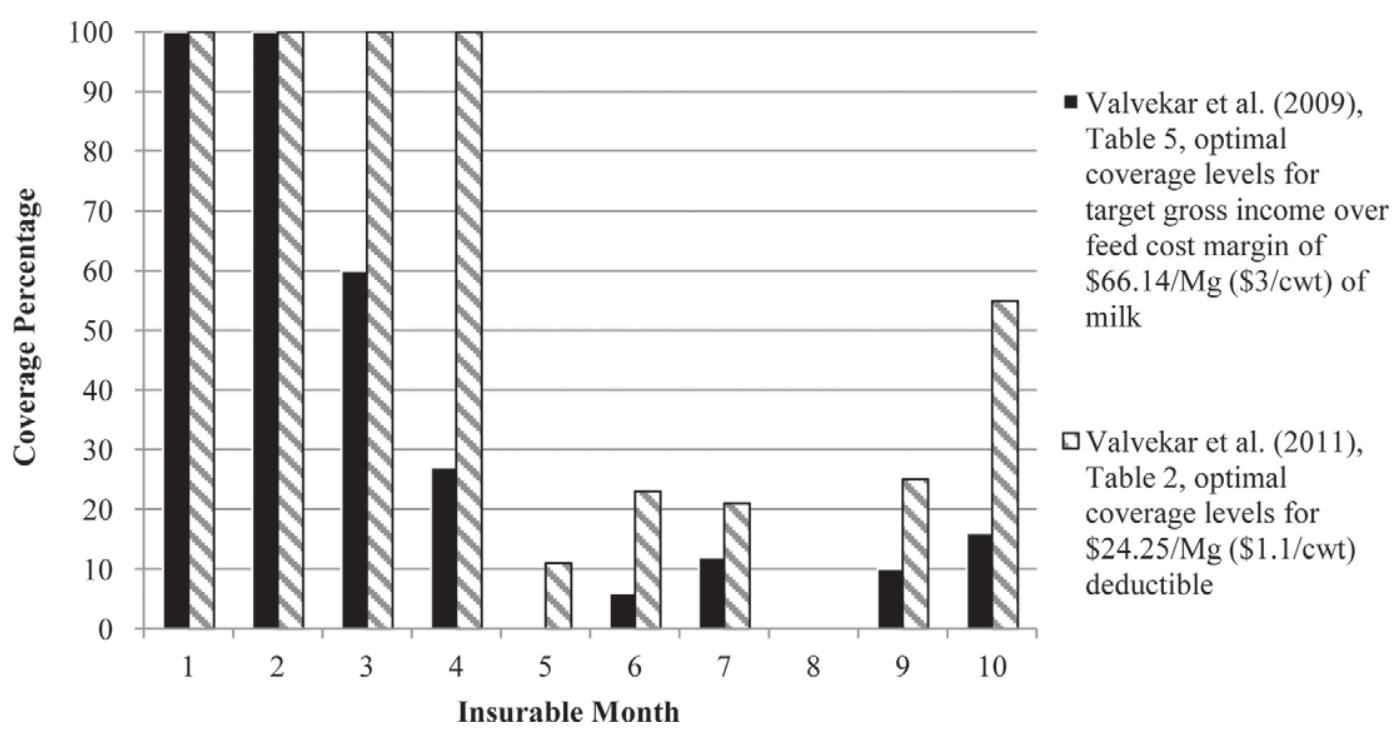

Figure 4. Patterns of coverage for Livestock Gross Margin (LGM) for Dairy Cattle cost-minimizing strategies (Valvekar et al., 2010, 2011).

in which first several insurable months are covered at a rate of $100 \%$, whereas for deferred months, coverage generally declines as the time to maturity increases. The intuition behind these patterns is that margin risk in deferred months is much higher, potential losses are larger, and consequently, it is more expensive to set a floor on a margin for a period that is, for example, 8 mo away than it would be for nearby months.

The optimal percentage coverage strategies illustrated in Figure 4 are single contract focused, and important hidden costs of these coverage strategies exist when one considers the short-run decision in the context of a longrun marketing plan. Buying LGM-Dairy insurance once a year, and obtaining insurance on the target IOFC margin by front-loading coverage on nearby months, exposes the producer to availability risk. That is, when the current insurance contract expires and it is time to buy coverage for the following year, good margins may not be available for purchase.

\section{RESULTS AND DISCUSSION}

To further explore the above hypothesis, we examined the potential efficacy of using LGM-Dairy to insure against 2009 declines in IOFC margins. We created 2 hedging profiles: Home-Feed and Market-Feed. The Home-Feed profile is used to represent dairy farms that grow most of their feed and may want to declare the minimum feed levels allowed within an LGM-Dairy contract $[0.07 \mathrm{~kg}$ of corn $/ \mathrm{kg}$ of milk $(0.13 \mathrm{bu} / \mathrm{cwt}$ of milk) and $0.0161 \mathrm{~kg}$ of soybean meal $/ \mathrm{kg}$ of milk (1.161 $\mathrm{lb} / \mathrm{cwt}$ )]. [A significant number of Wisconsin LGMDairy contracts have adopted this type of strategy (K.
Hartzell, Badgerland Financial, personal communication, July 2011). The Market-Feed profile is used to represent the other end of the spectrum, that is, dairy farms that buy all the feed for their dairy herd and would desire to declare the maximum allowable corn and soybean meal levels on the LGM-Dairy contract [0.76 kg of corn $/ \mathrm{kg}$ of milk (1.36 bu/cwt of milk) and $0.26 \mathrm{~kg}$ of soybean meal $/ \mathrm{kg}$ of milk $(26 \mathrm{lb} / \mathrm{cwt})]$. For both of these profiles, we examined 4 different contract designs in which, under each strategy, the producer purchases an LGM-Dairy contract each month and insures the following:

1. Flat 10: one-tenth of expected milk marketing for each of the 10 insurable months (i.e., the maximum number of months that can be covered by a single LGM-Dairy contract);

2. Up Front: one-third of expected milk marketing for the 1st, 2nd, and 3rd insurable months;

3. Middle of the Road: one-third of expected milk marketing for the 4th, 5th, and 6th insurable months; and

4. Looking Ahead: one-third of the expected milk marketing for the 8th, 9th, and 10th insurable months.

Regardless of the strategy adopted, as long as it is persistently followed, $100 \%$ of the expected milk marketing will eventually be insured under an LGM-Dairy contract.

In Figures 5 and 6, we illustrate the implications of using these 4 strategies for the Home-Feed and MarketFeed farm profiles in terms of the level of IOFC margin 
net of premium costs under the 4 alternative strategies. Our analysis encompasses the November 2007 through December 2009 period. To make the evaluation of these insurance strategies more tractable, we introduced several simplifications. First, although the first period when LGM-Dairy was available for purchase was August 2008, for the purpose of this exercise, we assumed LGM-Dairy was available as early as November 2007. Second, we assumed the operator chose a $\$ 24.25 / \mathrm{Mg}$ (\$1.10/cwt) deductible level, and that a $50 \%$ subsidy was available from contract inception. Finally, we assumed that the insurance premium was always due at the end of the last covered month. (Although the panels in Figure 5 show only the effects from October 2008 , for two of the hedging strategies examined, a risk management program would have to be put in place as early as November 2007 when October 2008 was the 10th insurable month.)

For each panel shown in Figure 5, we show the actual IOFC margin net of the premium paid, the amount of premium paid when no indemnity payments exist, and the net (of premium) indemnity received for months when the indemnity was due. When indemnity payments exist, the total level of the IOFC margin equals the sum of the actual margin and the net indemnity. To place these margins into perspective, it should be noted that over the 2000 to 2011 period, the average IOFC margin was $\$ 290.57 / \mathrm{Mg}$ (or $\$ 13.18 / \mathrm{cwt}$ ) for the HomeFeed farm type and $\$ 137.79 / \mathrm{Mg}$ (or $\$ 6.25 /$ cwt) for the Market-Feed farm type. In Table 2, we summarize the average per-tonne (per-hundredweight) margins for both profiles and under each of the 4 strategies.

Unprotected IOFC margins fell by $19.5 \%$ in 2009 compared with the 2000 to 2011 average for the HomeFeed type, and $63.7 \%$ for the Market-Feed farm type, respectively. Reflecting on the analysis of the IOFC margin behavior undertaken in the first part of this article, it should come as no surprise that the Up Front strategy resulted in a very modest increase in IOFC margins for both farm types. Income was increased by $\$ 15.87 / \mathrm{Mg}$ (\$0.72/cwt) for the Home-Feed producer compared with gross revenue that would have been realized if no LGM-Dairy contracts were purchased (no-LGM scenario). For the Market-Feed producer, income was increased by only $\$ 14.33 / \mathrm{Mg}$ (\$0.65/cwt) compared with the No-LGM scenario. The other strategies all performed rather well for the Home-Feed producer, with the Looking Ahead strategy being superior, with a full $\$ 88.85 / \mathrm{Mg}(\$ 4.03 / \mathrm{cwt})$ increase in average margins in 2009 compared with the no-LGM scenario. Comparing the panels in Figure 5, we see that for the Home-Feed farm type, the indemnity payments would have been significantly larger when using the Middle of the Road and Looking Ahead strategies than under either the Flat 10 or Up Front strategy.

It is not surprising that in Figure 6, where the results for the Market-Feed farm type are displayed, we see much lower IOFC margins. In fact, for July 2009 we actually would have observed a negative IOFC margin even under the Flat 10 strategy. As for the Home-Feed profile, under the Looking Ahead strategy, the average IOFC margins increased the most of the 4 strategies considered here. Under this strategy, the negative IOFC for June 2009 was increased from $-\$ 14.16 / \mathrm{Mg}(-\$ 0.64 / \mathrm{cwt})$ to $\$ 56.80 / \mathrm{Mg}(\$ 2.58 / \mathrm{cwt})$. For the entire 2009 year, the realized unprotected average margin was $\$ 50.10 / \mathrm{Mg}(\$ 2.27 / \mathrm{cwt})$, whereas the average margin under the Looking Ahead strategy was $\$ 83.23 / \mathrm{Mg}$ (\$3.78/cwt). Using the 2007 to 2011 average IOFC margins, we found that the Looking Ahead strategy reduced the 2009 shortfall in the IOFC margin by $93 \%$ for the Home-Feed profile and by $47 \%$ for the Market-Feed profile. For the purposes of this article, we deliberately kept the risk management strategies as simple as possible so as to illustrate the basic principles of effective IOFC margin smoothing. Higher protection for the Market-Feed profile in 2009 could have been achieved under a strategy that targeted a particular level of IOFC margin, rather than always choosing a particular deductible level. In the extreme case of a zero deductible, the Looking Ahead strategy average 2009 gross margin level that could be insured was $\$ 110.89 / \mathrm{Mg}$ (\$5.03/cwt), or $91 \%$ of the average 2007 to 2011 IOFC margin.

It should be noted that this analysis, although useful in expositing the basic fundamental principle of using distant-delivery contracts, is hypothetical in the sense that it assumes regular LGM-Dairy contract availability. In reality, between January 2011 and August 2012, LGM-Dairy was offered in only 5 sales events. The change in insurance rules and introduction of a premium subsidy in December 2010 has created an imbalance between demand for LGM-Dairy and available federal funds, rendering LGM-Dairy mostly unavailable for purchase. To illustrate the effect of this constraint, let us assume that farmers can buy LGM-Dairy only once a year, at the January sales event. If that were the case in 2009, then the highest margin the Home-Feed profile was able to insure would have been $\$ 245.37$ / $\mathrm{Mg}(\$ 11.13 / \mathrm{cwt})$ and $\$ 57.98 / \mathrm{Mg}(\$ 2.63 / \mathrm{cwt})$ for the Market-Feed profile. Those margins are only $\$ 11.02$ / $\mathrm{Mg}$ (\$0.50/cwt; Home-Feed) and \$7.96/Mg (\$0.36/ cwt; Market-Feed) higher than the realized 2009 IOFC margins in a scenario without any kind of protection. In the face of irregular LGM-Dairy availability, farmers may consider an alternative strategy, such as initiating 
a

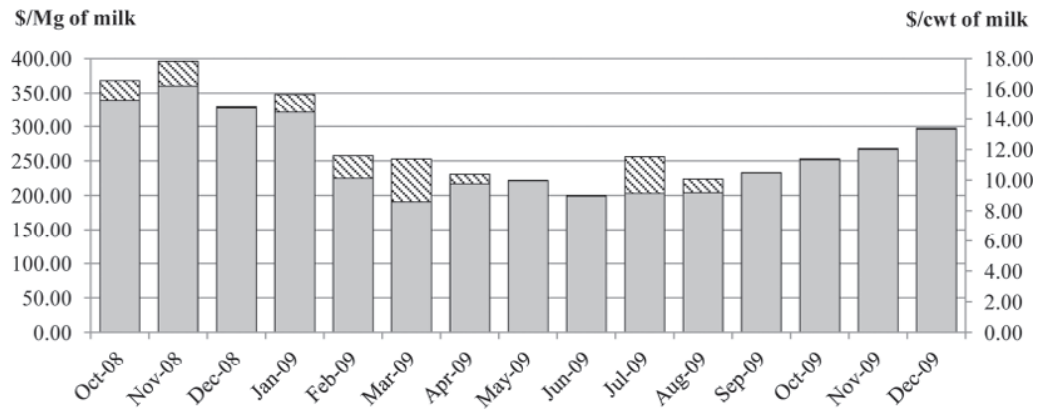

b

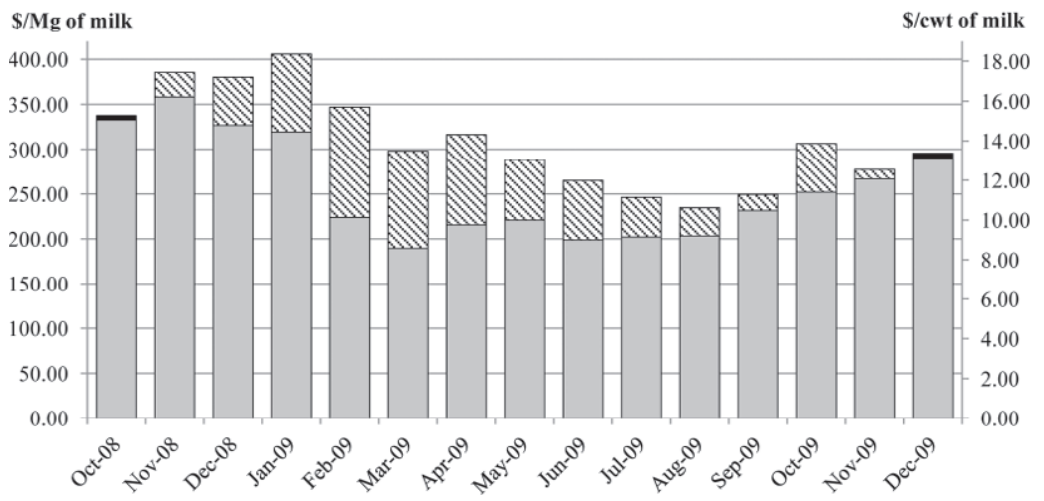

c

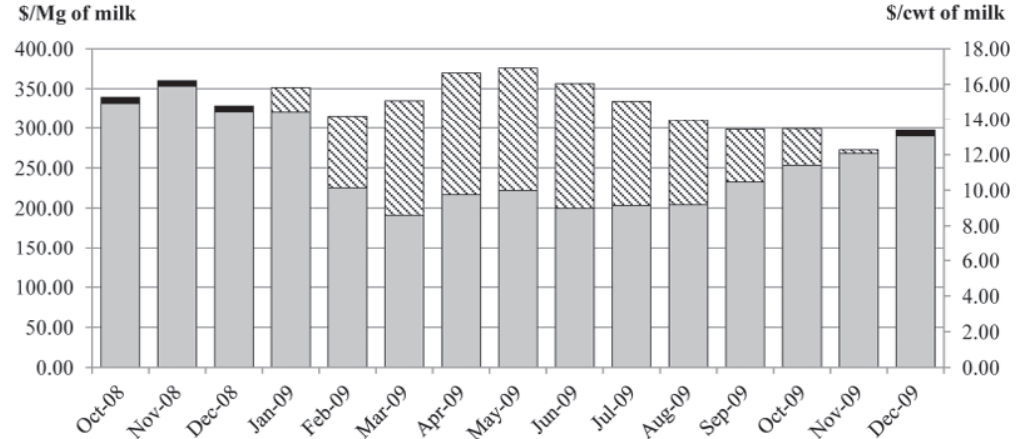

d

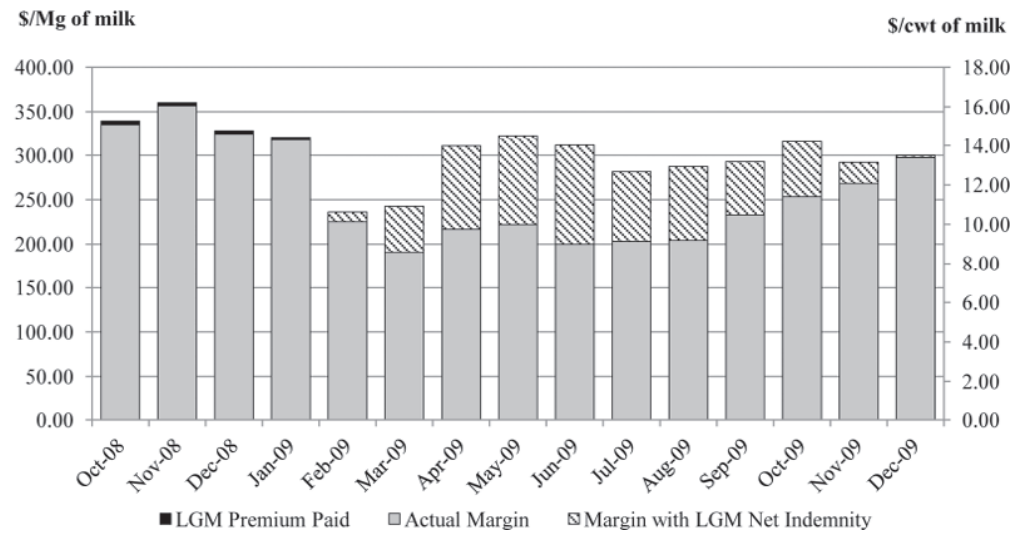

Figure 5. Income over feed cost (IOFC) margin smoothing under different risk management strategies: Home-Feed profile. (a) Up-Front strategy: insuring the first 3 insurable months; (b) Middle of the Road strategy: covering the 4th, 5th, and 6th insurable month; (c) Looking Ahead strategy: covering the 8th, 9th, and 10th insurable month; (d) Flat 10 strategy: covering all 10 insurable months via the Livestock Gross Margin Insurance for Dairy Cattle. 


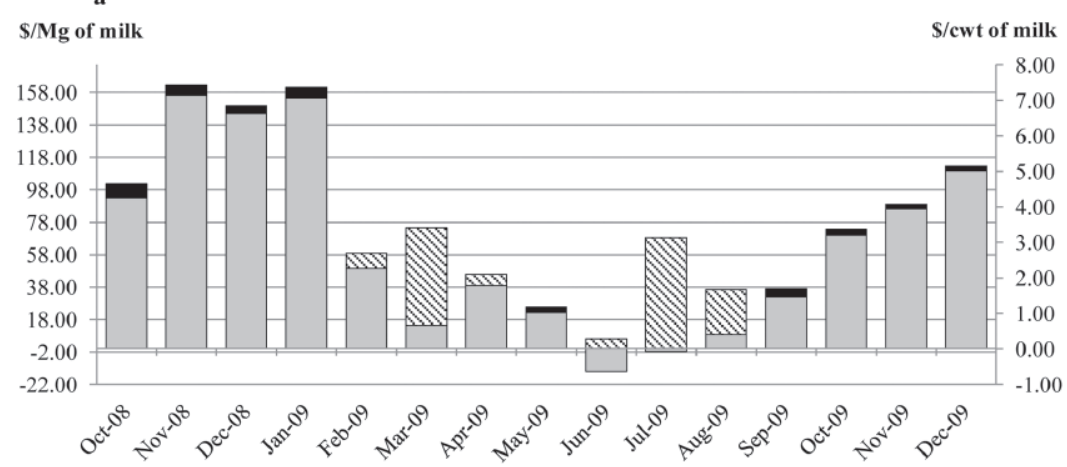

\$/Mg of milk $\$$ \$cwt of milk

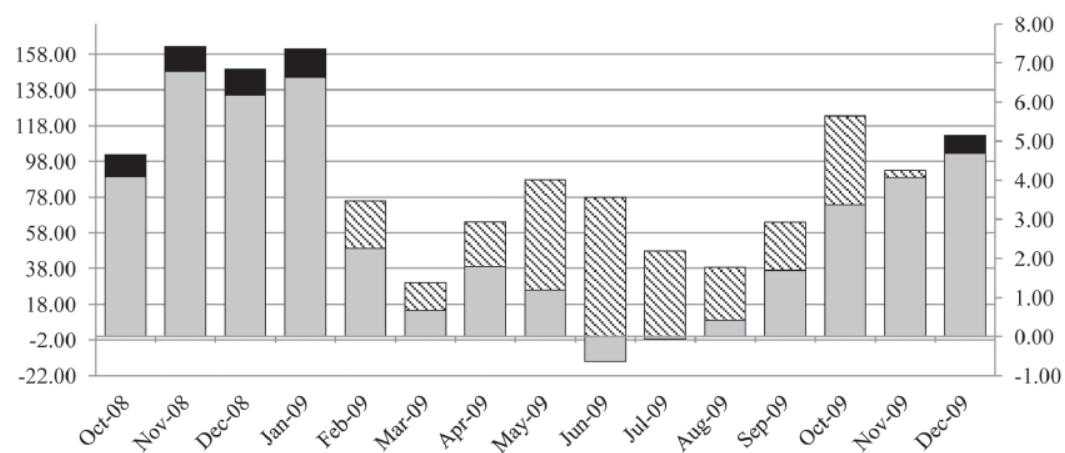

c

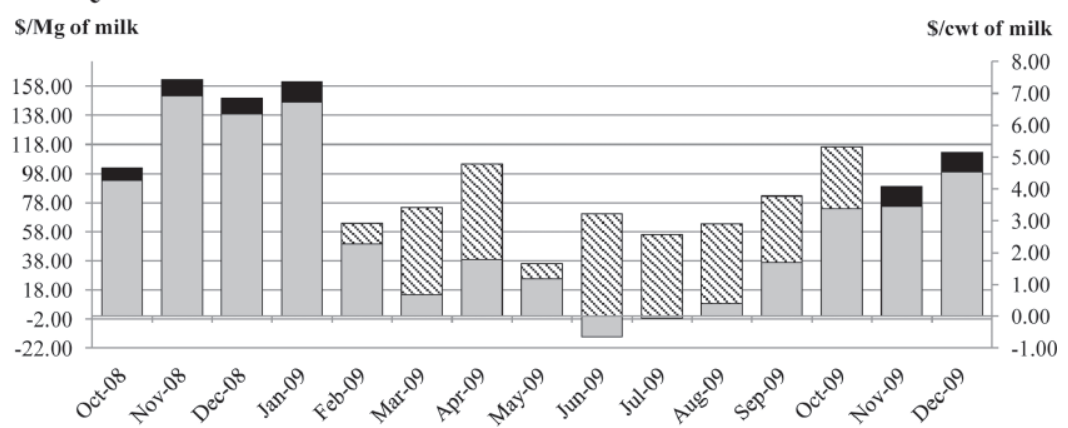

d

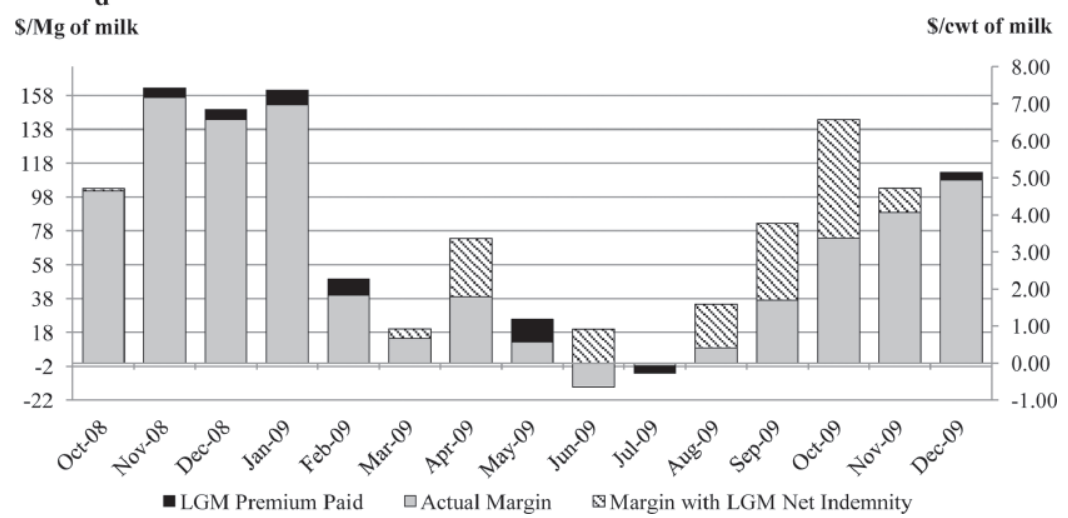

Figure 6. Income over feed cost (IOFC) margin smoothing under different risk management strategies: Market-Feed farm type. (a) Up-Front strategy: insuring the first 3 insurable months; (b) Middle of the Road strategy: covering the 4th, 5th, and 6th insurable months; (c) Looking Ahead strategy: covering the 8th, 9th, and 10th insurable month; (d) Flat 10 strategy: covering all 10 insurable months via the Livestock Gross Margin Insurance for Dairy Cattle. 
a limit order to buy a distant-delivery milk-feed option bundle once the IOFC margin exceeds a threshold they deem critical.

Another point worth emphasizing is that risk management should not be treated as a profit center in itself. The LGM-Dairy premiums are designed to be actuarially fair; that is, if used regularly, over the long run, indemnities paid on contracts purchased under a particular risk management strategy should be equal to the premiums paid. To illustrate the effect of buying actuarially fair insurance, consider the effect of LGMDairy on IOFC margins in 2007, a year with aboveaverage IOFC margins. In Table 2, we see that the smoothing effect is the strongest for the Looking Ahead strategy, with IOFC margins decreasing by more than twice the decrease under the Up Front approach. Overall, however, the cost of insurance seems rather reasonable, with the average per-hundredweight cost for 2007 IOFC margins at a very modest level of $\$ 0.16(\$ 3.53 /$ $\mathrm{Mg})$ for the Home-Feed profile and $\$ 0.23(\$ 5.29 / \mathrm{Mg})$ for the Market-Feed profile.

\section{CONCLUSIONS}

As the simulations undertaken in this article have shown, what may seem like an optimal strategy in the short run may, in fact, bring a producer to a situation in which no good alternatives are available for protection against an imminent and precipitous decline in IOFC margins. Hedging using nearby futures may help lock in above-average margins when times are good, but historically, only the consistent use of contracts with 9 to 12 mo to maturity would have sufficed to protect against prolonged periods of very low margins. Considering the forward IOFC margins based on the 2012 Farm Bill definition of a dairy production margin, over the 2000 to 2011 period, an opportunity always existed to lock in at least $\$ 154.32 / \mathrm{kg}(\$ 7.00 / \mathrm{cwt})$ if the margin protection had been initiated early enough. Buying a put option on the average gross margin, which can be done by using LGM-Dairy insurance, does not necessarily guarantee protection against a catastrophic risk. Front-loading the insurance policy to minimize costs of a target income over the feed margin within a single insurance contract carries the hidden cost that good margins will not be available for purchase when the current insurance contract expires. Nevertheless, producers that grow most of the required feed and those that buy all of it can successfully protect themselves against catastrophic gross margin risk if they consistently pursue risk management strategies that protect margins in those periods sufficiently far into the future that the current dynamics of supply and demand have 
little bearing on the purchase cost of the insurance contract and its availability.

\section{REFERENCES}

AgWeb. 2010. Dairy Producers Lost One Third of Their Equity in 2009. Accessed June 5, 2012. http://www.agweb.com/article/Dairy_ Producers_Lost_One_Third_of_Their_Equity_in_2009_194692/.

Bamba, I., and L. Maynard. 2004. Hedging-effectiveness of milk futures using value-at-risk procedures. Proceedings of the NCR-134 Conference on Applied Commodity Price Analysis, Forecasting, and Market Risk Management, St. Louis, MO. http://www.farmdoc.illinois.edu/nccc134/conf_2004/pdf/confp05-04.pdf.

Fortenbery, T. R., R. Cropp, and H. Zapata. 1997. Analysis of expected price dynamics between fluid milk contracts and cash prices for fluid milk. J. Agribus. 15:215-234.

Fortenbery, T. R., and H. Zapata. 1997. An evaluation of price linkages between futures and cash markets for cheddar cheese. J. Futures Mark. 17:279-301.

Gould, B., and V. Cabrera. 2011. USDA's Livestock Gross Margin Insurance for Dairy: What is it and How Can it be Used for Risk Management. Staff Paper 562. Dept. of Agric. and Appl. Econ., Univ. of Wisconsin-Madison. Accessed Sep. 1, 2011. http://www. aae.wisc.edu/pubs/sps/pdf/stpap562.pdf

Maynard, L., C. Wolf, and M. Gearhardt. 2005. Can futures and options markets hold the milk price safety net? Policy conflicts and market failures in dairy hedging. Rev. Agric. Econ. 27:273-286.

National Milk Producers Federation. 2010. Foundation for the Future: A New Direction for U.S. Dairy Policy. Natl. Milk Prod. Fed., Ar- lington, VA. http://dairy.wisc.edu/PubPod/Reference/Library/ NMPF-FFTF.2010.pdf.

Newton, J., and C. Thraen. 2012. Road block to risk managementHow federal milk pricing provisions complicate class 1 cross-hedging incentives. Proceedings of the NCCC-134 Conference on Applied Commodity Price Analysis, Forecasting, and Market Risk Management, St. Louis, MO. http://www.farmdoc.illinois.edu/ nccc134/conf_2012/pdf/confp09-12.pdf.

Nicholson, C. F., and M. W. Stephenson. 2010. Analysis of Proposed Programs to Mitigate Price Volatility in the U.S. Dairy Industry. Report to a Consortium of US Dairy Industry Organizations, September. Accessed Sep. 1, 2012. http://www.futurefordairy.com/ pdfs/Nicholson-and-Stephenson-Analysis.pdf.

Thraen, C. S. 1999. A Note: The CSCE cheddar cheese cash and futures price long-term equilibrium relationship revisited. J. Futures Mark. 19:233-244.

US House of Representatives. 2011. Dairy Security Act of 2011. US House of Representatives, Washington, DC.

Valvekar, M., V. Cabrera, and B. Gould. 2010. Identifying cost-minimizing strategies for guaranteeing target dairy income over feed cost via use of the Livestock Gross Margin dairy insurance program. J. Dairy Sci. 93:3350-3357.

Valvekar, M., V. Cabrera, M. Wattiaux, and B. Gould. 2010. Webbased feed-equivalent calculator based on the National Resource Council (2001) Nutrient Requirements of Dairy Cattle. Accessed June 5, 2012. http://dairymgt.info/lgmfeeds/index.html.

Valvekar, M., J. Chavas, B. W. Gould, and V. Cabrera. 2011. Revenue risk management, risk aversion and the use of livestock gross margin for dairy cattle insurance. Agric. Syst. 104:671-678. 